\title{
3D Printed Clamps for In Vitro Tensile Tests of Human Gracilis and the Superficial Third of Quadriceps Tendons
}

\author{
Ivan Grgić ${ }^{1, *(1)}$, Vjekoslav Wertheimer ${ }^{2,3}{ }^{\text {, Mirko Karakašić }}{ }^{1}$ and Željko Ivandić ${ }^{1}$ \\ 1 Mechanical Engineering Faculty in Slavonski Brod, University of Slavonski Brod, Trg Ivane Brlić Mažuranić 2, \\ 35000 Slavonski Brod, Croatia; mkarakasic@unisb.hr (M.K.); zivandic@unisb.hr (Ž.I.) \\ 2 Faculty of Medicine Osijek, Josip Juraj Strossmayer University of Osijek, Joispa Hutlera 4, \\ 31000 Osijek, Croatia; vjekoslav.wertheimer@gmail.com \\ 3 Department of Orthopedics and Traumatology, Osijek University Hospital, 31000 Osijek, Croatia \\ * Correspondence: igrgic@unisb.hr
}

check for updates

Citation: Grgić, I.; Wertheimer, V.; Karakašić, M.; Ivandić, Ž. 3D Printed Clamps for In Vitro Tensile Tests of Human Gracilis and the Superficial Third of Quadriceps Tendons. Appl. Sci. 2021, 11, 2563. https://doi.org/ 10.3390/app11062563

Academic Editor: Daniel X.B. Chen

Received: 4 February 2021

Accepted: 8 March 2021

Published: 12 March 2021

Publisher's Note: MDPI stays neutral with regard to jurisdictional claims in published maps and institutional affiliations.

Copyright: (c) 2021 by the authors. Licensee MDPI, Basel, Switzerland. This article is an open access article distributed under the terms and conditions of the Creative Commons Attribution (CC BY) license (https:// creativecommons.org/licenses/by/ $4.0 /)$.

\begin{abstract}
Recent soft tissue studies have reported issues that occur during experimentation, such as the tissue slipping and rupturing during tensile loads, the lack of standard testing procedure and equipment, the necessity for existing laboratory equipment adaptation, etc. To overcome such issues and fulfil the need for the determination of the biomechanical properties of the human gracilis and the superficial third of the quadriceps tendons, 3D printed clamps with metric thread profile-based geometry were developed. The clamps' geometry consists of a truncated pyramid pattern, which prevents the tendons from slipping and rupturing. The use of the thread application in the design of the clamp could be used in standard clamping development procedures, unlike in previously custom-made clamps. Fused deposition modeling (FDM) was used as a 3D printing technique, together with polylactic acid (PLA), which was used as a material for clamp printing. The design was confirmed and the experiments were conducted by using porcine and human tendons. The findings justify the usage of 3D printing technology for parts manufacturing in the case of tissue testing and establish independence from the existing machine clamp system, since it was possible to print clamps for each prepared specimen and thus reduce the time for experiment setup.
\end{abstract}

Keywords: metric thread profile; 3D printed clamps; uniaxial tensile test; porcine flexor tendon; human gracilis tendon; human quadriceps tendon

\section{Introduction}

Because of the viscoelastic characteristics of soft tissue and the low friction between the clamp material and wet soft tissues, it was hard to hold them properly at in vitro loads and at the required loading speed. Excessive compression on the soft tissue will elevate stress around the contact area, which leads to rupture before the target loads are achieved. Less compression will result in slippage [1]. The first successful attempt to prevent such problems has been solved with the "cryo-jaw" clamps, as presented by Riemersa and Schamhardt [2]. They used clamps made of brass connected with four M8 screws to compress the tendon ends, followed by freezing via the circulation of liquid carbon dioxide. Sharky et al. [3] applied a similar method on the quadriceps and Achilles tendons without slippage and with no apparent compression problems. Schatzmann et al. [4] used water in the containment chamber, and then (after waiting for the water to be frozen) proceeded with testing of the human quadriceps tendon-bone complexes and patellar ligament-bone complexes. Due to complex freezing equipment, other researches have reported some different solutions. Cheung and Zhang [5] have presented the nonfrozen serrated jaw clamp made of serrated plastic material. Shi et al. [6] have reported that their new type of nonfrozen tendon clamps could sustain the targeted tensile force of $4.0 \mathrm{kN}$ by holding the tendon firmly without any slippage, with a maximal sustainable tensile force as high as $6.87 \mathrm{kN}$. This new type of clamp is easy to manufacture and use, as it is small in size and 
cheap in cost. It can be a good alternative to the complex frozen clamps in the biological simulation tests of muscular activity in musculoskeletal systems. $\mathrm{Ng}$ et al. [7] tested and evaluated several gripping methods, including a serrated jaw, sandpaper, frozen ends and air-dried ends on $1 \mathrm{kN}$ Shimadzu pneumatic grips. They have found that by using the pneumatic grips with the cardboard lining, the stress concentration at the grip-specimen interface reduced substantially. By reviewing the available literature, the necessity for existing laboratory equipment to adapt in order to properly execute tissue experiments was also noticeable. Steinke et al. [8] reported slippage as a major issue during the tests using the original machine clamps. For a biomechanical comparison of quadriceps and patellar tendon grafts, Shani et al. [9] used the cryo-grips attached to the linear actuator of the MTS servohydraulic test machine (MTS Systems, Eden Prairie, MN). The cryofixation device with its water containment chamber mounted on a universal testing machine (Instron Model 1270, Loadcell Instron Model 2518, High Wycombe, Bucks, UK) is reported in [4]. More such device variations can be seen in [10-12]. The existence of slipping and rupturing problems, in addition to the lack of standardization, different testing protocols, and custommade testing devices were the motivation for our study. We investigated whether there was any mechanical engineering field that could help to solve these issues. To our knowledge, there is no such study presented in the available literature, since most of these prior studies were based on customization.

Additive production is the process by which a product is made by adding material layer by layer based on data from 3D models. It is considered one of the key development technologies, providing new approaches to production and providing the finished product relatively quickly. It allows us to make very complex geometric products that would be very difficult to create with classical procedures. Current advancements in tissue engineering and regeneration, therapeutic delivery, medical device fabrication and operative management planning ensure that additive manufacturing will continue to play an increasingly important role in the future of healthcare [13]. Currently, fused deposition modeling (FDM) 3D printing is the most popular method for the fabrication of polymer composites. First, the STL file from the CAD model of an object is imported to the slicer software to set up all the necessary printing parameters, such as printing speed, nozzle temperature, layer height and the generation of the G-code for communication with the $3 \mathrm{D}$ printer. In FDM, the raw material is pushed out through a nozzle while pressure is applied. In this process, a spool of thermoplastic filament must be melted and extruded through a high-temperature nozzle. The layers used in the additive production process are created by extruding molten material onto the substrate. It is necessary to bind the material with previous material in order to produce a solid component. In the FDM process, different thermoplastic materials (such as acrylonitrile butadiene styrene (ABS), nylon, polylactic acid (PLA) and polycarbonate) can be used [14]. The 3D printing technique not only enables the fabrication of complex structures in a timely and cheap manner but also allows for the manufacture of composites with various combinations of compositions [15]. The literature review of the $3 \mathrm{D}$ printing techniques used in medicine is presented below. Wood et al. [16] proposed an innovative clamp design that utilizes fairly recently available technology (i.e., 3D printing) to produce a made-to-measure tendon sleeve that encloses the sample ends and also enables straightforward alignment within the testing equipment. All experiments were carried out using the superficial digital flexor tendons obtained from the hind pig legs. The sleeve was designed in such a way as to reduce slippage by introducing perfectly interlocking serrations. This has the advantage of evenly distributing the pressure on the tendon, thereby reducing the risk of stress concentration. In the paper presented by Scholze et al. [17], the authors used quasistatic tensile tests combined with digital image correlation and fatigue trials to characterize the applicability of the current clamping technique using 3D printed clamps. They reported that the 3D printed clamps showed no signs of clamping-related failure during the quasistatic tests and the fatigue tests and that the material slippage was low. A comparison to other clamping techniques shows that the 3D printed clamps ease and expedite specimen handling, are 
highly adaptable to the varying specimen geometries and are ideal for high-standardization and high-throughput experiments in soft tissue biomechanics. They used a clamp design with 4 -sided pyramid structures in a cross-sectional view. For all 3D prints, the parts were produced with 100-micron layers using a $0.4 \mathrm{~mm}$ brass nozzle. The clamps were printed in an upright position in order to produce a lateral orientation of the pyramids, allowing for these surface structures to have a very detailed quality. The material used for the clamps' $3 \mathrm{D}$ printing was polylactic acid (PLA). Furthermore, in another paper [18] from the same authors, the standardized tensile testing procedure using a 3D printed clamping system used in [17] was presented. In addition, the following examples show that the application of 3D printing technology is not new to medicine and it is not limited to one specific area of interest. However, due to its accessibility, it is significantly useful in helping to understand the human body in general. In [19] it was used for the 3D printing of a titanium periacetabular implant with horseshoe-shaped plates, in [20] to depict organ-tumor relations and even possibly used for control-based $4 \mathrm{D}$ printing in medicine in [21]. What follows are some relevant issues related to FDM printing: visible layer lines, poor part strength, nozzle radius limits, high surface roughness, temperature fluctuation issues, support material and structure [14].

The background of this work is dealing with medial patellofemoral ligament (MPFL) injury, classified as a dislocation of the patella. It is emphasized that this injury occurs, on average, for 5.8 per 100,000 persons per year, and that number is growing (it is as high as 29 in 100,000 people between 10 and 17 years of age). MPFL injury causes a complex injury in medial structures. The treatment is performed by an operative procedure, completely removing the damaged ligament and replacing it with a tendon [22]. This is the reason for using human gracilis and quadriceps tendons in this study, since future work will be dealing with the biomechanical properties of these tendons and their correlation with the MPFL.

By considering the previous literature review, it was necessary to deal with several topics, such as the utilization of existing laboratory equipment and its tissue testing possibilities. The avoidance of arbitrary choice in any design step was important as well. Special emphasis was given to the geometry of the clamps. Could the clamp geometry be based on the mechanical engineering field and possibly be used in consideration for the future standardization of procedure, since there are currently no standards used in tissue testing? This will be discussed below.

\section{Workspace and Thread Selection}

\subsection{Analysis and Measurement of the Laboratory Equipment}

After reassembling the lower pneumatic grip from the Shimadzu AGS-X $10 \mathrm{kN}$ tensile test machine, analysis and measurement of the grip parts was conducted. It was determined that the clamps have two holes with $\mathrm{M} 4 \times 1 \mathrm{~mm}$ internal thread ( $4 \mathrm{~mm}$ deep), while the bore is $7 \mathrm{~mm}$ deep. The middle bore is $16 \mathrm{~mm}$ in diameter and $4 \mathrm{~mm}$ deep (Figure 1). The same procedure was done for the upper pneumatic grip and clamps. The maximum space between the two clamps on the pneumatic grips has been considered to see how much space is available in case the $3 \mathrm{D}$ printed clamps are required to act as extensions.

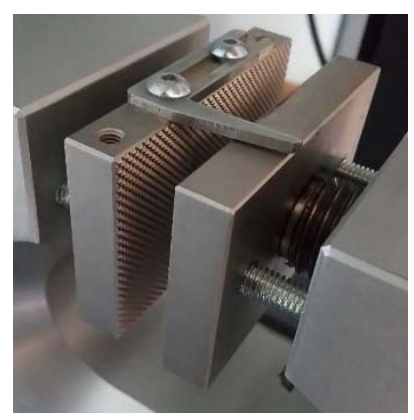

Figure 1. The original clamps on the Shimadzu AGS-X $10 \mathrm{kN}$ machine. 


\subsection{Brief Thread Profile Analysis}

A difference exists between normal threads and fine threads. The fine threads have a small profile depth, so it is doubtful that they will hold the tendon tight enough between the clamps. Therefore, preference was given to the normal threads. Whitworth threads are very similar in profile to metric threads, so preference was given to the use of metric threads, due to their wide application ability. Square profile threads are harder to make and there are no standards for their manufacture, so they were excluded from further analysis. Buttress threads are particularly suitable for receiving unilateral compressing forces. Their flanks, which are perpendicular to the direction of pressure, receive longitudinal forces better than the sharp threads do, so they were also selected for analysis. The trapezoidal threads were also selected for analysis.

\section{Clamp Modeling, 3D Printing and Mounting}

The first attempt was based on the original clamp dimensions and their geometry. The $3 \mathrm{D}$ printed clamps were designed with the thread profile geometry modeled on the front face of the clamps. Mounting on the grips was successful (Figure 2), but the clamps failed during specimen compression at the screw insertion spots.

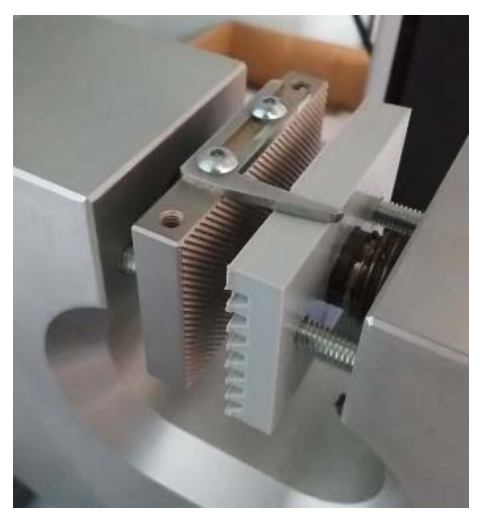

Figure 2. The $3 \mathrm{D}$ printed clamp paired with the original one.

The second attempt was based on the case of the clamps acting as extensions. When looking at the side view of the original clamp previously shown in Figure 1, they were considered to have a cross-sectional view of one half of a bolt. If the same amount of the additional material (the 3D printed clamps) is added, the thickness will rise. It looked like a bolt $40 \mathrm{~mm}$ in diameter with (according to that measurement) an appropriate metric M42 $\times 4.5 \mathrm{~mm}$ (M40 is not listed into a group of normal metric threads by the literature), trapezoidal Tr40 $\times 3 \mathrm{~mm}$ and buttress S40 $\times 3 \mathrm{~mm}$ external thread according to DIN 103, and it was chosen. Therefore, the "bolt" axis was put on one side of the clamp and on the other the thread profile. All models were processed with the free Ultimaker Cura slicing application before printing, and the low-cost Creality Ender-2 3D printer was used. All models were printed in the upright position $\left(90^{\circ}\right)$ [15], using the polyethylene terephthalate glycol (PET-G), a commercially available biodegradable material with 200-micron layers and a $0.4 \mathrm{~mm}$ brass nozzle. The temperature of the nozzle was set to $225^{\circ} \mathrm{C}$ and $60^{\circ} \mathrm{C}$ for the printing base. During the pretests, the clamps showed promising behavior, and it was chosen for use for further examinations. The 3D printed clamps are presented in Figure 3. 


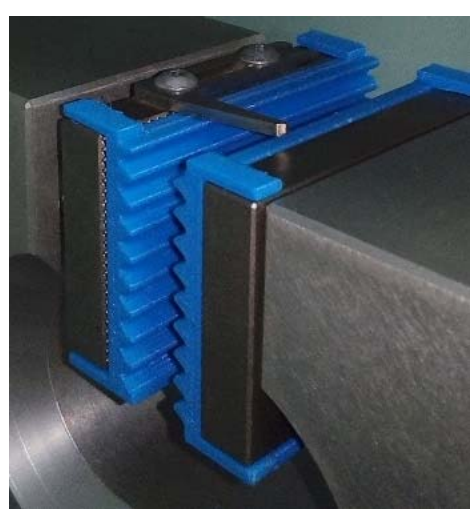

Figure 3. 3D printed clamps as extensions.

\section{Uniaxial Tensile Tests of Porcine Tendons}

Forty-two porcine superficial flexor tendons were obtained from an abattoir within $2 \mathrm{~h}$ of slaughter. After removing all connective tissue, the tendons were isolated, stored in airtight plastic bags and put in the freezer at $-80{ }^{\circ} \mathrm{C}[23,24]$. Before testing, the specimens were thawed in water while they were still left in their plastic bags to avoid any contact with the water during the thawing process (which lasted around $30 \mathrm{~min}$ ). Each specimen was dried out with a soft rag to remove any surface moisture. Fourteen specimens were selected randomly for each of the three clamping methods (i.e., metric, trapezoidal and buttress), due to the differences in their length and the intention not to cut them to the same length considering their manner of dissection. Seven of them were left in their natural shape and seven of them were formed into a dog-bone shape, per each clamp type. To form the dog-bone shape, the cutting area was marked (Figure 4). Subsequently, five markers were put on the specimen surface (three of them to serve as guiding points for the cutting curves and the other two for positioning the clamp ends).
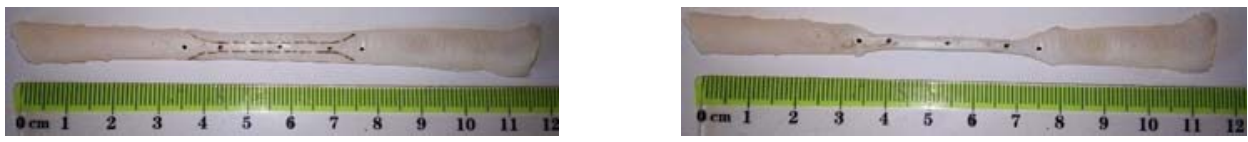

Figure 4. Preparation of the specimen (markers on the surface-left, dog-bone shaped specimen—right).

The same procedure was used for the tendons left in their natural shape, without the dog-bone cutting pattern. The length and the cross-section area (assumed to be the elliptic/natural shape and the quadratic/dog-bone shape) were measured five times, and the mean value was used for each specimen. The specimens were mounted on the tensile test machine. The gauge length was approximately $35 \mathrm{~mm}$. The pressure applied to the grippers was set at 3 bar $(720 \mathrm{~N}$ of clamping force). The specimens were preloaded with a $2 \mathrm{~N}$ force and preconditioned by a series of 10 cycles, starting from the undeformed position $(0 \mathrm{~mm})$ and going up to a stroke of $1.5 \mathrm{~mm}$, with a stroke rate of $10 \mathrm{~mm} / \mathrm{min}$ maintained to reduce tissue hysteresis $[23,24]$. Five minutes after the preconditioning phase, the tendons were tested until failure. First, they were preloaded with a $2 \mathrm{~N}$ force to remove slack. Secondly, zero force and movement were established, and, finally, the test started with a stroke rate of $10 \mathrm{~mm} / \mathrm{min}$ until specimen failure. The setup of the experiment is presented below in Figure 5, with the tendon in its natural shape. 


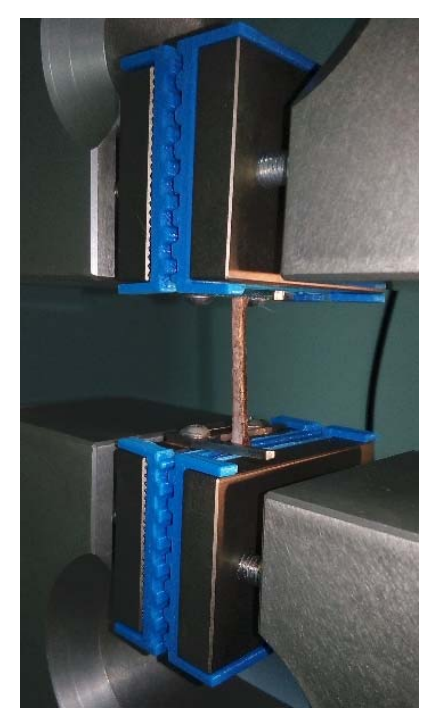

Figure 5. Setup of the experiment.

The mean values of the ultimate tensile strength, stroke strain and structural modulus were measured. Note that the structural modulus and ultimate stroke strain differ from the actual elastic modulus and ultimate strain of the tendon, as they were based on the crosshead motion of the grippers. According to [7], for the relative comparison between different clamps, this can be used. All presented data have been extracted from the Trapezium X software. The specimens left in their natural shape will be denoted as T1-T21, while the specimens prepared in the dog-bone shape will be denoted as T1-d.b.-T21-d.b.

The focus of the investigation was on which type of the designed clamps would meet the following conditions set out as acceptance terms: (a) The design of the clamp should be accepted if there were no signs of slipping and rupturing during the uniaxial tensile tests; (b) The design of the clamp should be accepted if at least one error (either slipping or rupturing) does not occur during uniaxial tensile tests; (c) The design of the clamp should not be accepted if slipping and rupturing do occur during the uniaxial tensile tests.

If the first condition is met, a further change in the clamp design will not be considered and further testing on human tendons will be considered. If the second condition is met, a further change in the clamp design will be considered and tested. With this term, there has been left space for further design ideas. If the third condition is met, a further change in the clamp design will not be considered and tested. For a better presentation of the results in the tables and diagrams, only the designs that have fully met the first condition will be shown, and the rest will be classified as rejected even if they satisfy the second condition.

\subsection{Clamps Based on the Trapezoidal Thread Profile}

All of the tests that included the dog-bone shaped specimens finished without slipping. There were no specimen ruptures in the clamping area and all failed in their mid-substance area. Among the seven natural shaped specimens, one failed in its mid-substance area and three failed at the point where they leave the clamping area. Smith et al. [25] compared the mean ultimate tensile strength of tendons failing at the clamp with the mean ultimate tensile strength of those failing in the mid-substance and found no significant differences between the ultimate tensile strength of the "clamp failures" and the "mid-failures". They suggested that the data from the clamp failure tests could also be included with the data from the mid-failure tests. Slippage of approximately $10 \mathrm{~mm}$ and rupture in the clamping area occurred within three natural shape specimens (Figure 6). These specimens have been excluded from further observation, and the results are presented in Table 1. The typical tendon tensile test curves and the last tenth cycle of the hysteresis curves are shown in Figure 7. 

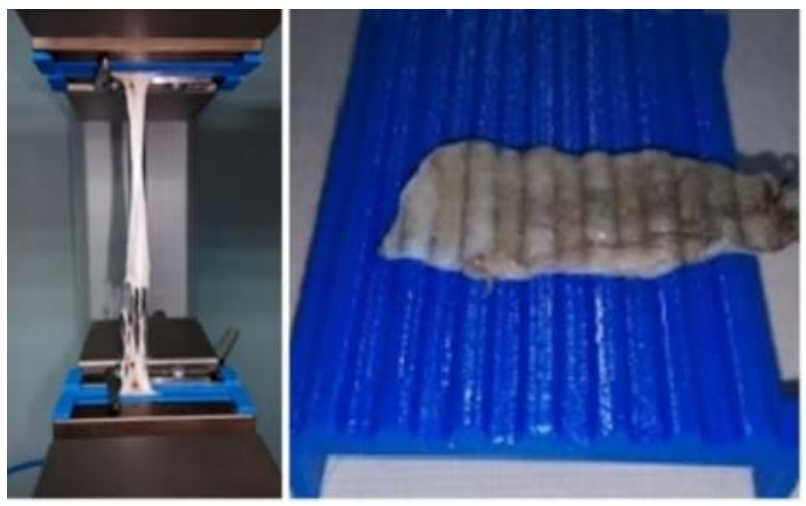

(a)

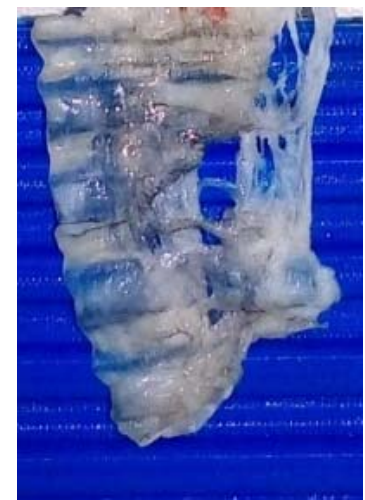

(b)

Figure 6. Tendon failure and tissue in the clamping area (a) and tissue rupture (b).

Table 1. Biomechanical properties achieved with the use of "trapezoidal" clamps.

\begin{tabular}{cccccc}
\hline The Shape of the Specimen & $\boldsymbol{n}$ & Rejected & $\begin{array}{c}\text { Ultimate Tensile Strength, } \\
\mathbf{M P a}\end{array}$ & Stroke Strain, \% & $\begin{array}{c}\text { Structural Modulus, } \\
\mathbf{M P a}\end{array}$ \\
\hline Natural & 7 & 3 & $34.78(9.11)$ & $32.29(7.57)$ & $160.31(50.94)$ \\
Dog-bone & 7 & - & $50.16(13.51)$ & $30.04(6.10)$ & $254.73(68.24)$ \\
\hline
\end{tabular}

(SD) Standard Deviation.

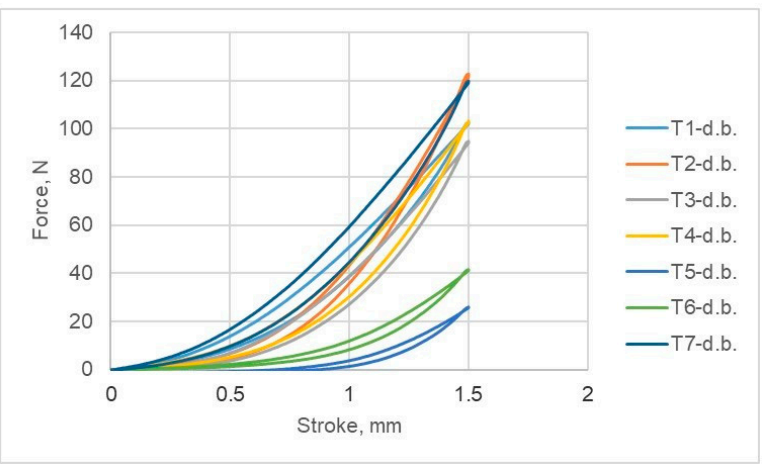

(a)

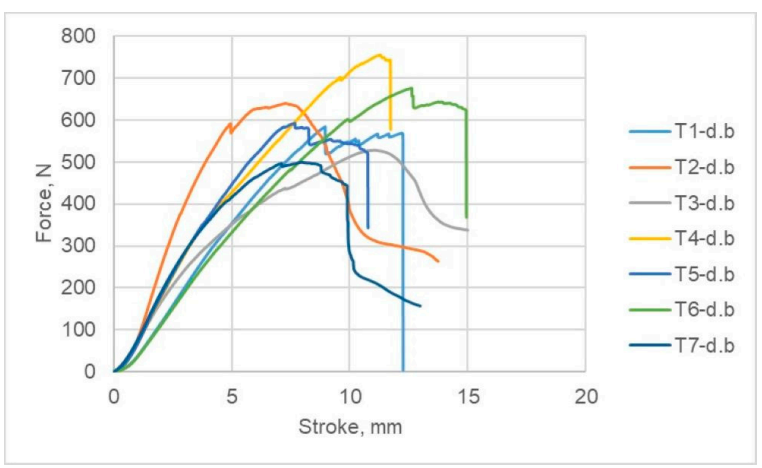

(c)

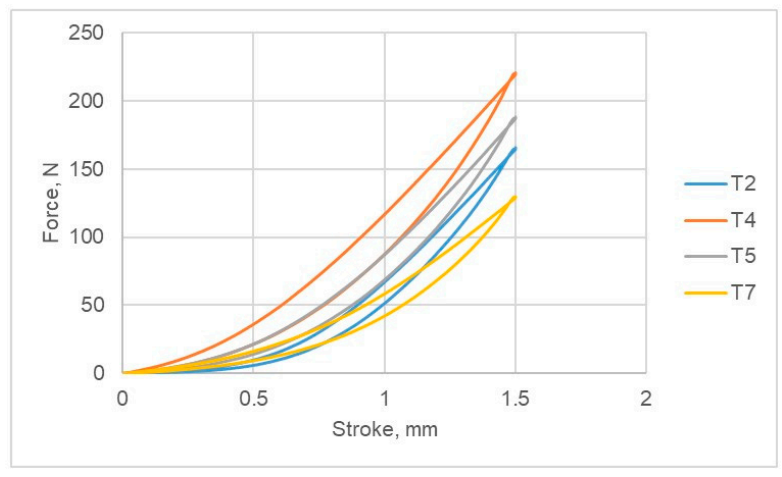

(b)

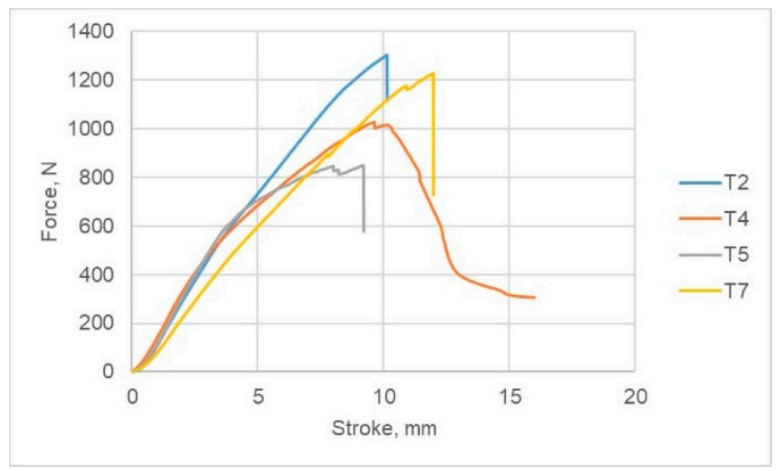

(d)

Figure 7. (a) Tenth cycle of hysteresis curves of the dog-bone specimens; (b) tenth cycle of hysteresis curves of specimens in their natural form; (c) tensile tests of dog-bone shaped specimens; (d) tensile tests of specimens in their natural shape, (Figure 4). 
One test of the dog-bone shaped specimen finished with slipping, three specimens failed in the mid-substance area and three specimens failed at the point where the tendon leaves the clamping area. No specimen ruptures were found. Among the seven natural shaped specimens, two specimens failed in the mid-substance area and three failed at the point where the specimen leaves the clamping area. A slippage of $2 \mathrm{~mm}$ occurred in two tests without ruptures, and these specimens were thusly excluded from analysis. The results are presented in Table 2 . The typical tendon tensile test curves and the last tenth cycle of the hysteresis curves are shown in Figure 8.

Table 2. The biomechanical properties achieved with the use of "metric" clamps.

\begin{tabular}{cccccc}
\hline The Shape of the Specimen & $\boldsymbol{n}$ & Rejected & $\begin{array}{c}\text { Ultimate Tensile Strength, } \\
\text { MPa }\end{array}$ & Stroke Strain, \% & $\begin{array}{c}\text { Structural Modulus, } \\
\text { MPa }\end{array}$ \\
\hline Natural & 7 & 2 & $41.12(6.44)$ & $22.49(3.31)$ & $104.98(47.14)$ \\
Dog-bone & 7 & 1 & $41.68(5.39)$ & $23.74(3.66)$ & $236.09(66.50)$ \\
\hline
\end{tabular}

(SD) Standard Deviation.

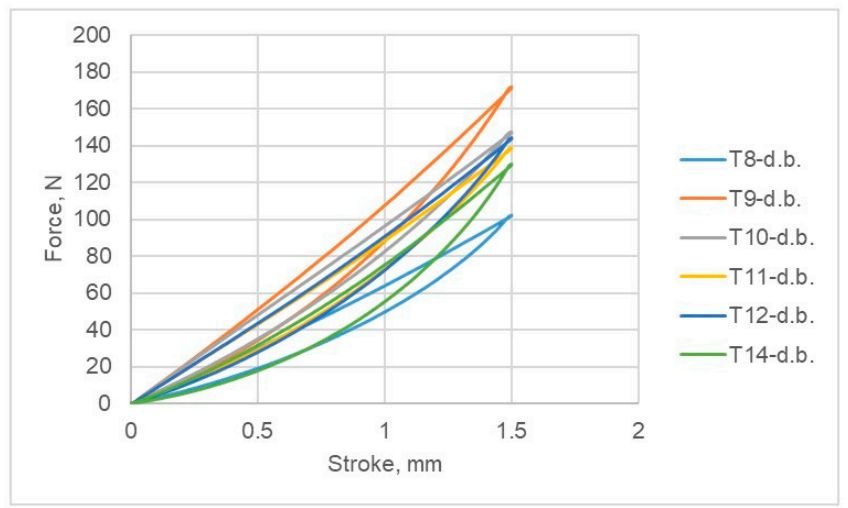

(a)

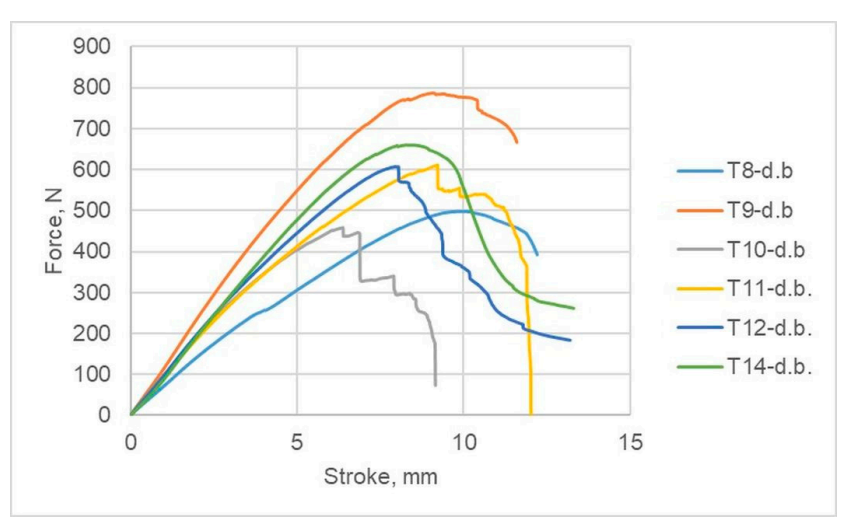

(c)

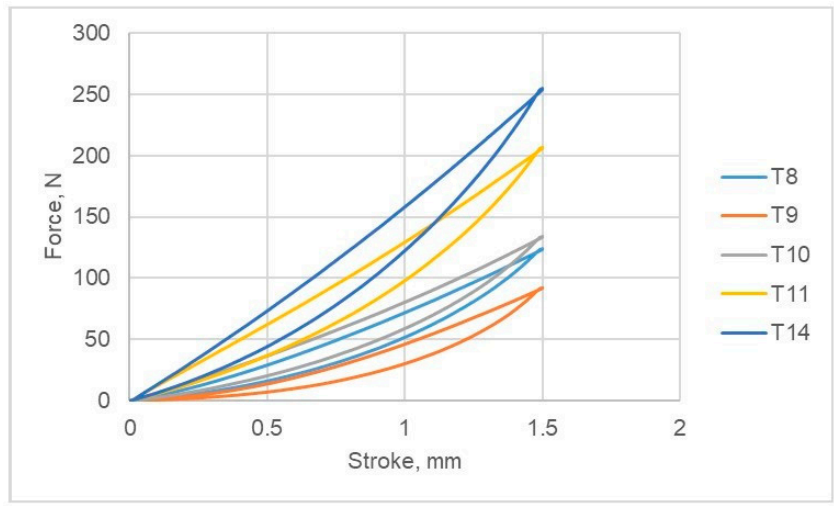

(b)

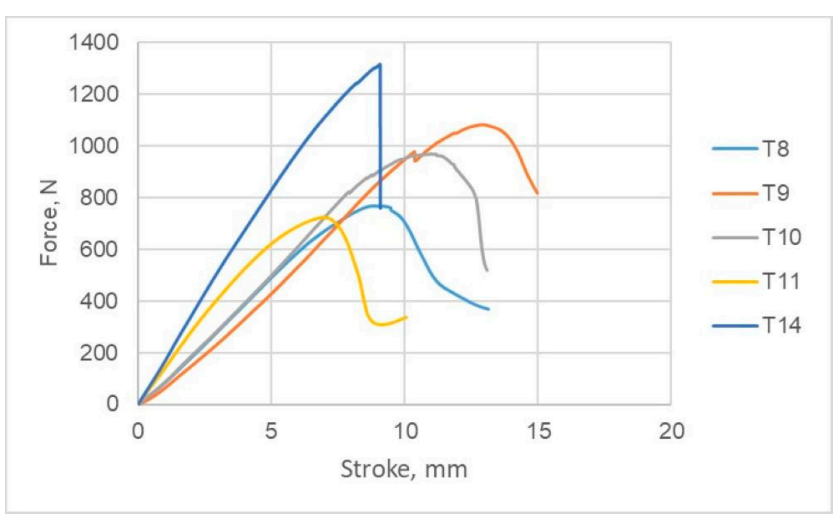

(d)

Figure 8. (a) Tenth cycle of hysteresis curves of dog-bone specimens; (b) tenth cycle of hysteresis curves of specimens in their natural form; (c) tensile tests of dog-bone shaped specimens; (d) tensile tests of specimens in their natural shape.

\subsection{Clamps Based on the Buttress Thread Profile}

Among the seven dog-bone shaped specimens, one was excluded due to slipping and one was excluded because it had a bad geometry (the cuts were caused by an imprecise dissection). Four of the specimens failed in the mid-substance area and the last one failed at the point where the tendon exits the clamping area. The slipping cases and the rupturing cases in the clamping area occurred in the two natural shape specimens. The reported 
slippage was $3 \mathrm{~mm}$ long in both cases. The rest failed in the mid-substance area. The results are presented in Table 3. The typical tendon tensile test curves and the last tenth cycle of hysteresis curves are shown in Figure 9.

Table 3. Biomechanical properties achieved with the use of "buttress" clamps.

\begin{tabular}{cccccc}
\hline The Shape of the Specimen & $\boldsymbol{n}$ & Rejected & $\begin{array}{c}\text { Ultimate Tensile Strength, } \\
\mathbf{M P a}\end{array}$ & Stroke Strain, \% & $\begin{array}{c}\text { Structural Modulus, } \\
\mathbf{M P a}\end{array}$ \\
\hline Natural & 7 & 2 & $30.75(16.79)$ & $26.96(2.05)$ & $108.04(53.81)$ \\
Dog-bone & 7 & 1 & $55.73(3.96)$ & $24.31(3.96)$ & $304.62(48.89)$ \\
\hline
\end{tabular}

(SD) Standard Deviation.

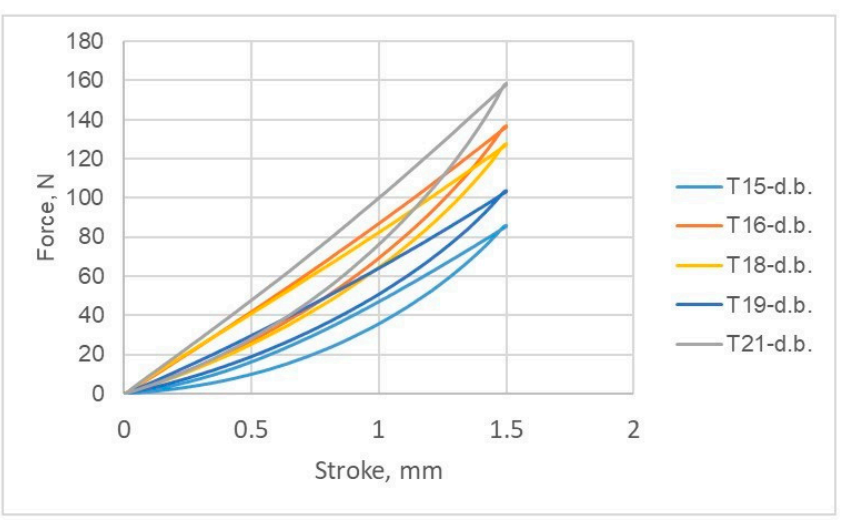

(a)

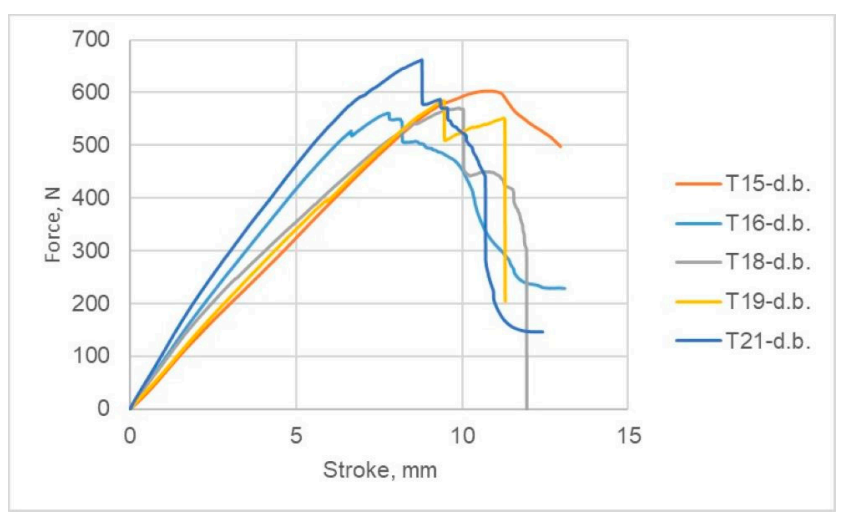

(c)

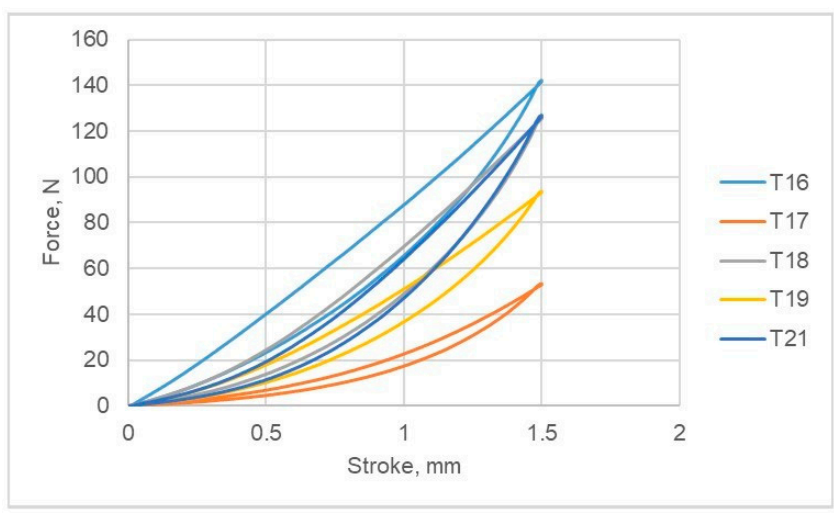

(b)

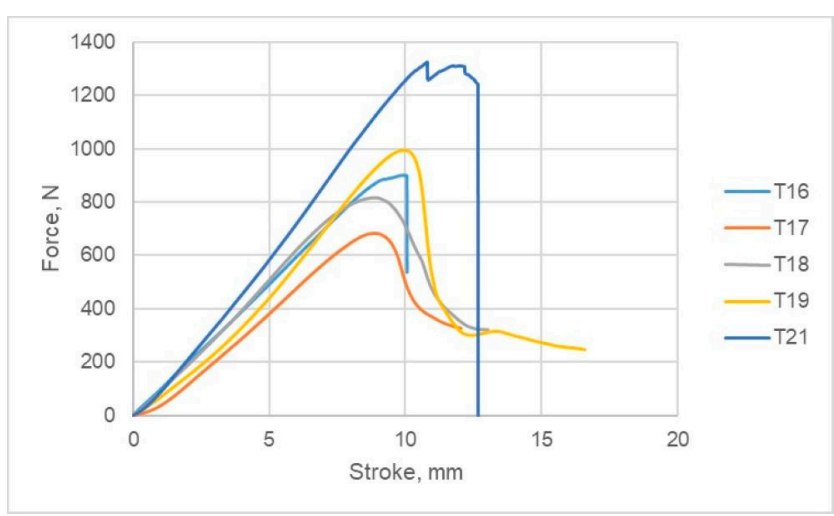

(d)

Figure 9. (a) Tenth cycle of hysteresis curves of dog-bone specimens; (b) tenth cycle of hysteresis curves of specimens in their natural form; (c) tensile tests of dog-bone specimens; (d) tensile tests of specimens in their natural shape.

Since the first term could not be met, after analysis of the second term was conducted, it was established that the clamps' geometry (with the application of the metric thread profile) will be used for further analysis. Compared to other types of clamps, there were no signs of rupture in the clamping area, which points to a good stress distribution over the tendon tissue in the clamping area, but the slippage is the problem that persists. This will be discussed below.

\section{3D Printed Clamps for Tensile Test of Human Tendons}

\subsection{Clamp Characteristics}

By referring to [17], a decision was made to use a pattern over the inner side of the clamping surface based on the metric thread profile. The thread profiles will be positioned diagonally in regards to the clamp, intersecting each other, unlike in previously designed 
clamps with the thread profile patterns parallel to each other. This type of clamp design will be tested further to prevent the tendons from slipping. The thickness of the clamps is $10 \mathrm{~mm}$. It represents one half of the diameter of the screw on which the thread is to be modeled. Therefore, the selected metric thread profile has M20 thread characteristics. The profile of the metric thread was modeled diagonally to prevent slippage and satisfy the conditions from the previously conducted experiments. The bigger holes on the clamps are used to put the bolts through to affix the tendon in between. Figure 10 shows the other specifications of the clamps. In order to mount the clamps to the tensile test machine, custom grippers were designed, 3D printed and mounted on the tensile test machine. The model of the clamps' assembly, together with the tendon, is shown in Figure 11.

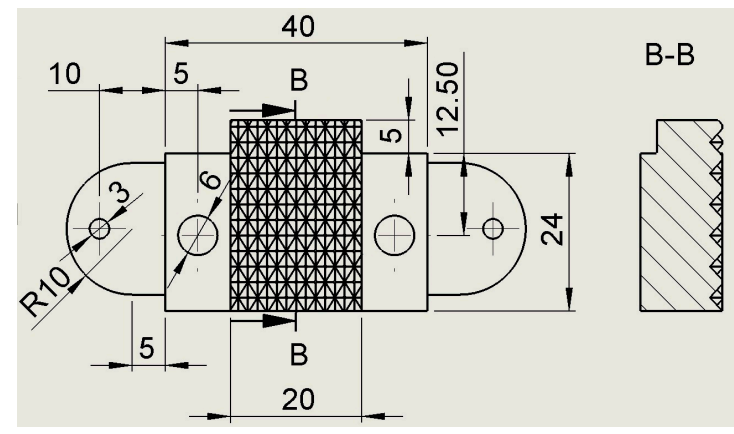

(a)

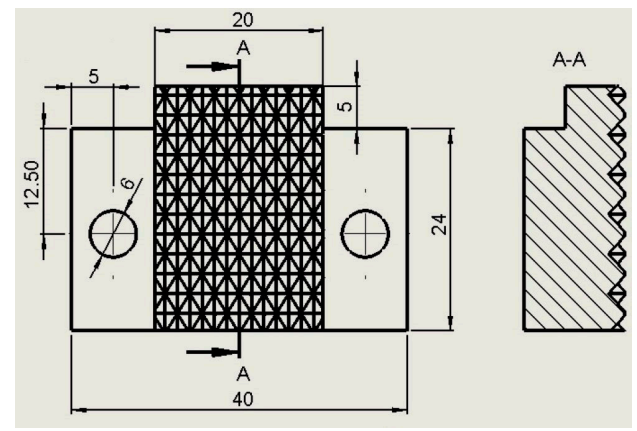

(b)

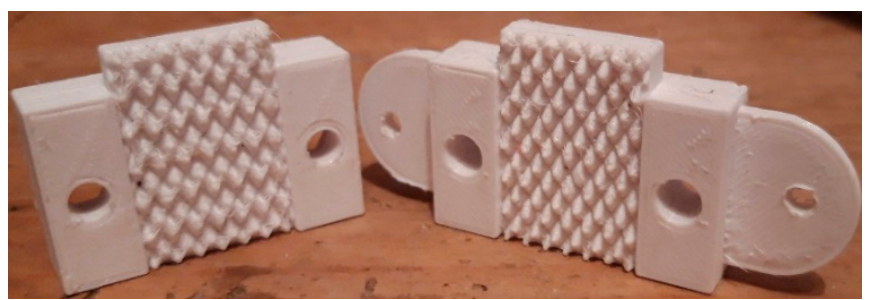

(c)

Figure 10. (a) First clamp-side dimensions, rounded parts and holes; (b) second clamp-side dimensions; (c) the physical models of the clamps.

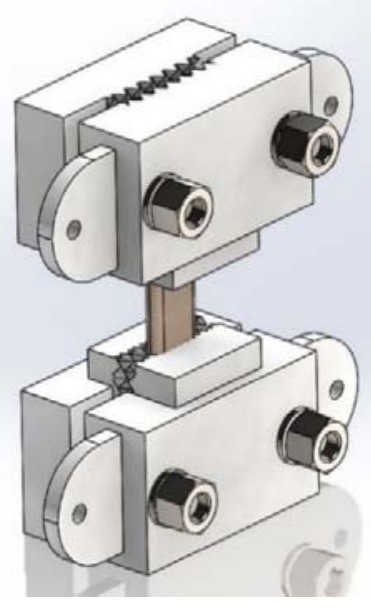

(a)

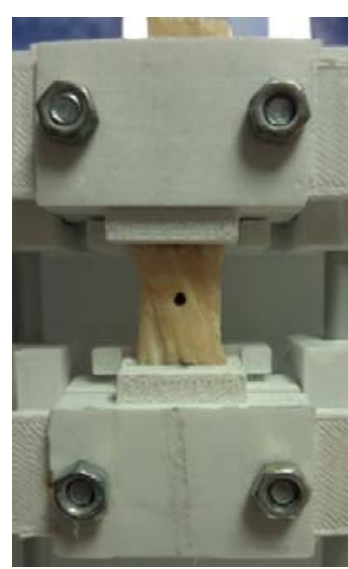

(b)

Figure 11. (a) The CAD assembly model with clamps and a tendon; (b) The physical assembly model with clamps and a tendon. 


\subsection{D Printing Process of Clamps}

For 3D printing, all models were exported as an STL file. They were then processed with the free Ultimaker Cura slicing application before being printed using the low-cost Creality Ender-2 3D printer. All models were printed to form the pyramids in the upright position $\left(\right.$ at $0^{\circ}$ ) [15] using PLA, a commercially available biodegradable material with 200-micron layers and a $0.4 \mathrm{~mm}$ brass nozzle. The temperature of the nozzle was set to $210{ }^{\circ} \mathrm{C}$ and $60^{\circ} \mathrm{C}$ for the build plate. In general, the 3D printing parameters are presented below in Figure 12.
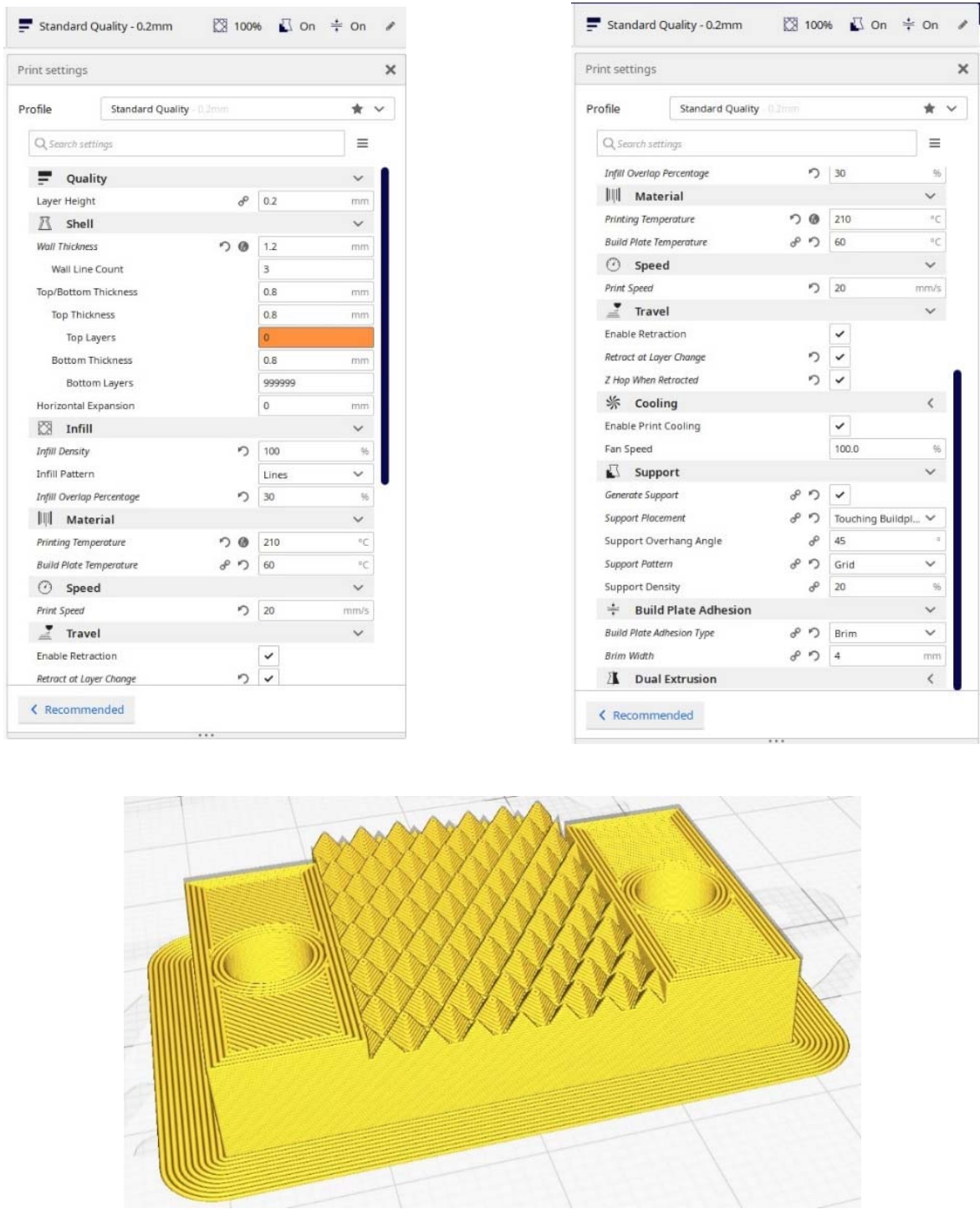

Figure 12. The set of parameters for $3 \mathrm{D}$ printing and clamp view in the slicer [26].

\subsection{Experiment Procedure}

16 human tendons ( 8 gracilis tendons and 8 superficial third quadriceps tendons) were obtained from the University of Osijek anatomy laboratory. After removing all connective tissue, the tendons were isolated and stored in airtight plastic bags and put in the freezer at $-80^{\circ} \mathrm{C}$. Before testing, the specimens were thawed in Ringer's solution. Each specimen was dried out with a soft rag to remove any surface moisture, and the cross-sectional area was measured five times, using the digital micrometer with $0.05 \mathrm{~mm}$ accuracy (using the rectangular cross-section area for the quadriceps and the elliptical cross-section area for the gracilis tendons). The mean value of these calculations was used. The next step was establishing optical control of the tendon tissues using a digital microscope camera $(0.3 \mathrm{~m}$ 
CMOS, 2MP, $1000 \times$ optical zoom) to eventually find dissection errors; there were no signs of tissue damage. Three markers were put on the specimen surface. The upper marker and the lower marker represent the points where the specimen leaves the clamping area. The specimens were mounted on the tensile test machine in the custom-made grips. The pressure applied to the grippers was set to 3 bar. The specimens were preloaded with a $2 \mathrm{~N}$ force and preconditioned by a series of 10 cycles starting from the undeformed position $(0 \mathrm{~mm})$ up to a stroke of $1.5 \mathrm{~mm}$, with a stroke rate of $10 \mathrm{~mm} / \mathrm{min}$ maintained to reduce tissue hysteresis $[23,24]$. After the preconditioning phase, the tendons were tested until failure. First, they were preloaded with a force of $2 \mathrm{~N}$ to remove slack, at which point zero force and movement were established and the gauge length was $25 \mathrm{~mm}$. The test started with a $10 \mathrm{~mm} / \mathrm{min}$ stroke rate until specimen failure was induced. All 16 specimens failed approximately in the mid-substance area and were tested in their natural shape. No slippage and tissue rupture within the clamping area were found. An example of the finished tensile test is shown below in Figure 13. The results of the tensile tests for both types of human tendons are shown in Table 4.

Table 4. The biomechanical properties of the human tendons.

\begin{tabular}{cccccc}
\hline The Type of the Specimen & $\boldsymbol{n}$ & Rejected & $\begin{array}{c}\text { Ultimate Tensile Strength, } \\
\mathbf{M P a}\end{array}$ & Stroke Strain, \% & $\begin{array}{c}\text { Structural Modulus, } \\
\mathbf{M P a}\end{array}$ \\
\hline Gracilis & 8 & - & $82.57(8.41)$ & $21.41(2.15)$ & $458.81(93.89)$ \\
Quadriceps & 8 & - & $40.71(7.75)$ & $14.75(1.17)$ & $387.44(71.88)$ \\
\hline
\end{tabular}

(SD) Standard Deviation.

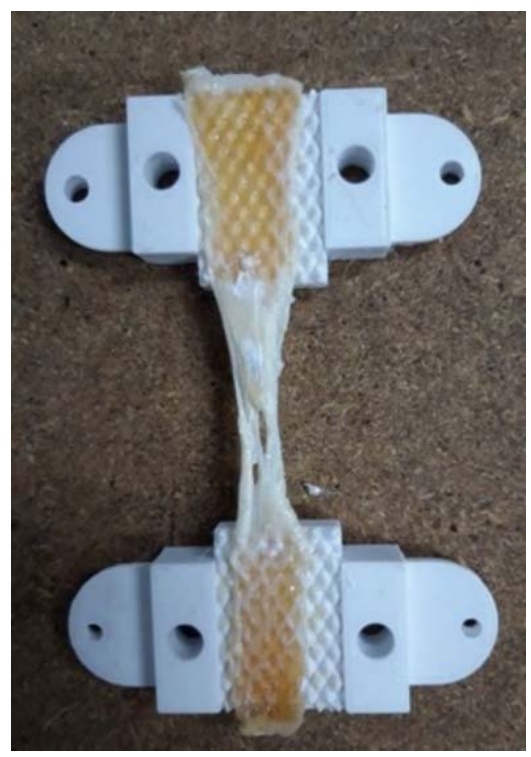

Figure 13. Clamping area and specimen failure.

\section{Discussion}

In this study, an innovative clamp design based on the metric thread profile was proposed and manufactured using fused deposition modeling (FDM) as a 3D printing technique for the future determination of the biomechanical properties of the human gracilis and quadriceps tendons. Unlike those produced by conventional material processing, the clamps that were 3D printed were very user-friendly in terms of material, time and production cost, supervising, office implementation, reusability and biofriendliness [17]. The idea for the clamping technique to use bolts for clamps connection was taken from [5]. The average 3D printing time was $2 \mathrm{~h}$ and $30 \mathrm{~min}$ per clamp. The infill was set to $100 \%$ with a $0.2 \mathrm{~mm}$ layer height. The consumption of PLA material was $13 \mathrm{~g}$ (or $4.46 \mathrm{~m}$ ) for a clamp with a rounded part and $11 \mathrm{~g}$ (or $3.36 \mathrm{~m}$ ) for a clamp with the other part. 
The printing temperature was set to $210{ }^{\circ} \mathrm{C}$ and $60{ }^{\circ} \mathrm{C}$ for the printing base. During printing, no issues were found. A good clamping behavior was noticed during tests and no damage to the clamps was found. By printing the clamps for each prepared specimen, the time required for machine setup and calibration was significantly reduced because we had specimens tightened in the clamps in advance, as presented in $[17,18]$. Unlike those in other studies $[3,6,7,16-18]$, this design is based on a well-known part from the field of mechanical engineering. With the lack of standardization in the determination of tissue biomechanical properties, the approach presented in this study could contribute to solving that issue. As much as is possible, the intention of this study was to achieve the same bone-tendon-muscle complex as exists in the human body. We achieved the clamp-tendon-clamp complex with the flaring sides of the tendon tissue (which is similar to the bone-tendon-muscle complex found in the human body and is reported in $[17,18]$ as well). The most important outcome for us has been to mimic the anatomy of the human body, since our future experiments will be dealing with determining the biomechanical properties of human gracilis and quadriceps tendons and their correlation with the medial patellofemoral ligament (MPFL) to discover which of these tendons can serve as the best MPFL replacement in the case of patella dislocation. By searching the literature and relevant scientific bases, we did not find any such replacement and we are still looking for the best testing protocol and the most suitable equipment. We did not reach any conclusion through statistical analysis. The next important issues to address are tendon slipping and rupturing. We solved these problems by intersecting the metric thread profile and obtained a pattern full of truncated pyramids, very similar to the one reported in [17] with sharp pyramids, but without the associated slipping. The recommendation for conducting these tests on the thin/thick specimen is to use the flat/sharp pyramid patterns [18]. We found that a truncated pyramid pattern was the most suitable. In the case of porcine tendons, the stress concentrations occurred during the clamping procedure (caused by excessive pressure and/or clamp geometry), causing misalignment of the collagen fibers within the tissue towards the direction of the tensile force. Such stress inequalities cause tendon rupturing and slipping (Figure 6). In this case, this can be reduced via changing the amount of pressure applied and/or the clamping technique. In this study, the clamping techniques were observed, but the pressure parameter should be considered in future work. Furthermore, from the literature review and reported studies, it is obvious that the commercially available testing equipment cannot be used for tissue testing as they are currently. This process demands the additional development and integration of different modules in its workspace, as achieved in this study.

This study has certain limitations. To avoid the possible appearance of corrosion in our equipment, we could not prevent tendons from dehydration by spraying them during testing. We also wanted to proceed with the creep and stress-relaxation tests and fatigue tests, but since these are long-lasting tests and we could not provide ongoing tissue moistening, these tests were not performed. While creating a dog-bone shaped specimen (as inspired by the sample preparation presented by Herbert et al. [27]), in some cases, we had problems achieving a well-shaped cross-section area, so we should use or create some special tool which could help us with this issue, like the one found in $[17,18]$. We achieved the shape of the cross-section area of the tendons and we had to custom-make the grippers suitable for fixing the clamps in the tensile test machine (which will be discussed in our future work). Finally, this type of clamp system has to be tested on the other types of tendons and ligaments. Tests without the bolts' pretension established will also be necessary if someone uses the presented method only for pattern modeling and the machine grips for clamping instead of the bolts.

Author Contributions: Conceptualization, I.G. and V.W.; methodology, I.G. and V.W.; validation, I.G. and V.W.; formal analysis, V.W.; investigation, I.G.; resources, V.W.; data curation, I.G.; writingoriginal draft preparation, I.G.; writing—review and editing, M.K.; supervision and review, Ž.I. All authors have read and agreed to the published version of the manuscript. 
Funding: This research received no external funding.

Institutional Review Board Statement: The study was conducted according to the guidelines of the Declaration of Helsinki, and approved by the Ethics Committee of Josip Juraj Strossmayer University of Osijek (number: 2158-61-07-19-17, date of approval 30 April 2019).

Informed Consent Statement: Not applicable.

Data Availability Statement: Not applicable.

Acknowledgments: The authors acknowledge the support of the Bebrinka d.o.o company for the donation of porcine tendons.

Conflicts of Interest: The authors declare no conflict of interest.

\section{References}

1. Arndt, A.; Kom, P.; Brüggemann, G.; Lukkariniem, J. Individual muscle contributions to the in vivo Achilles tendon force. Clin. Biomech. 1998, 13, 532-541. [CrossRef]

2. Riemersa, D.; Schamhardt, H. The cryo-jaw, a clamp designed for in vitro rheology studies of horse digital flexor tendons. J. Biomech. 1982, 15, 619-620. [CrossRef]

3. Sharky, N.; Smith, T.; Lundmark, D. Freeze clamping musculotendinous junctions for in-vitro simulation of joint mechanics. J. Biomech. 1995, 28, 631-635. [CrossRef]

4. Schatzmann, L.; Brunner, P.; Stäubli, H. Effect of cycling preconditioning of the tensile properties of human quadriceps tendons and patellar ligaments. Knee Surg. Sports Traumatol. Arthrosc. 1998, 6, 56-61. [CrossRef] [PubMed]

5. Cheung, J.; Zhang, M. A serrated jaw clamp for tendon gripping. Med. Eng. Phys. 2006, 28, 379-382. [CrossRef]

6. Shi, D.F.; Wang, D.M.; Wang, C.T.; Liu, A. A novel, inexpensive and easy to use tendon clamp for in vitro biomechanical testing. Med. Eng. Phys. 2012, 34, 516-520. [CrossRef] [PubMed]

7. Ng, B.; Chou, S.; Krishna, V. The influence of gripping techniques on the tensile properties of tendons. J. Eng. Med. 2005, 5, 349-354. [CrossRef] [PubMed]

8. Steinke, H.; Lingslebe, U.; Böhme, J.; Slowik, V.; Shim, V.; Hädrich, C.; Hammer, N. Deformation behaviour of the iliotibial tract under different states of fixation. Med. Eng. Phys. 2012, 34, 1221-1227. [CrossRef]

9. Shani, R.H.; Umpierez, E.; Nasret, M.; Hiza, E.A.; Xerogeanes, J. Biomechanical Comparison of Quadriceps and Patellar Tendon Grafts in Anterior Cruciate Ligament Reconstruction. Arthrosc. J. 2016, 32, 71-75. [CrossRef]

10. Dominick, C.; Herbort, M.; Raschke, M.J.; Schliemann, B.; Siebold, R.; Śmigielski, R.; Fink, C. Converting round tendons to flat tendon constructs: Does the preparation process have an influence on the structural properties? Knee Surg. Sports Traumatol. Arthrosc. 2017, 25, 1564-1567. [CrossRef]

11. Kousa, P.; Järvinen, T.L.N.; Vihavainen, M.; Kannus, P.; Järvinen, M. Tendon Fixation Strength of Six Hamstring Tendon Graft Fixation Devices in Anterior Cruciate Ligament Reconstruction. Am. J. Sports Med. 2003, 31, 174-181. [CrossRef]

12. Herbert, A.; Jones, G.L.; Ingham, E.; Fisher, J. Decellularisation and Sterilisation Effects on the Viscoelasticity of Porcine Super Flexor Tendons. In Proceedings of the ORS 2014 Annual Meeting, New Orleans, LA, USA, 15-18 March 2014.

13. Ahangar, P.; Cooke, E.M.; Weber, H.M.; Rosenzweig, H.D. Current Biomedical Applications of 3D Printing and Additive Manufacturing. Appl. Sci. 2019, 9, 1713. [CrossRef]

14. Khosravani, M.R.; Reinicke, T. On the environmental impacts of 3D printing technology. Appl. Mater. Today 2020, 20 , 1-11. [CrossRef]

15. Li, T.; Chen, Y.; Wang, L. Enhanced fracture toughness in architected interpenetrating phase composites by 3D printing. Compos. Sci. Technol. 2018, 167, 251-259. [CrossRef]

16. Wood, M.; Casha, A.; Gatt, A.; Formosa, C.; Chockalingman, N.; Grima, J.; Gatt, R. 3D Printed Clamps to Study Mechanical Properties of Tendon at Low Strains. Phys. Status Solidi 2019, 256, 1-8.

17. Scholze, M.; Singh, A.; Lozano, P.; Ondruschka, B.; Ramezani, M.; Werner, M.; Hammer, N. Utilization of 3D printing technology to facilitate and standardize soft tissue testing. Sci. Rep. 2018, 8, 1-13. [CrossRef]

18. Scholze, M.; Safavi, S.; Chun Li, K.; Ondruschka, B.; Werner, M.; Zwirner, J.; Hammer, N. Standardized tensile testing of soft tissue using a 3D printed clamping system. HardwareX 2020, 8, e00159. [CrossRef]

19. Park, D.W.; Lim, A.; Park, J.W.; Lim, K.M.; Kang, H.G. Biomechanical Evaluation of a New Fixation Type in 3D-Printed Periacetabular Implants using a Finite Element Solution. Appl. Sci. 2019, 9, 820. [CrossRef]

20. Seok, J.; Yoon, S.; Ryu, H.C.; Ryu, J.; Kim, S.; Jung, Y.S. Mesh-Type Three-Dimensional (3D) Printing of Human Organs and Tumors: Fast, Cost-Effective, and Personalized Anatomic Modeling of Patient-Oriented Visual Aids. Appl. Sci. 2021, $11,1047$. [CrossRef]

21. Zolfagharian, A.; Kayanak, A.; Bodaghi, M.; Kouzani, A.Z.; Gharaie, S.; Nahavandi, S. Control-Based 4D Printing: Adaptive 4D-Printed Systems. Appl. Sci. 2020, 10, 3020. [CrossRef]

22. Matijević, M. Rekonstrukcija Medijalnog Patelofemoralnog Ligamenta na zavodu za Ortopediju KBC Osijek od 2011 . do 2016. Godine. Master's Thesis, Josip Juraj Strossmayer University of Osijek, Osijek, Croatia, 2017. 
23. Smeets, K.; Slane, J.; Scheys, L.; Claes, S.; Bellemans, J. Mechanical Analysis of Extra-Articular Knee Ligaments. Part One: Native knee ligaments. Knee 2017, 24, 949-956. [CrossRef]

24. Smeets, K.; Bellemans, J.; Scheys, L.; Eijnde, O.B.; Slane, J.; Claes, S. Mechanical Analysis of Extra-Articular Knee Ligaments. Part Two: Tendon grafts used for knee ligament reconstruction. Knee 2017, 24, 957-964. [CrossRef] [PubMed]

25. Smith, C.; Young, L.; Kearny, J. Mechanical properties of tendons: Changes with sterilization and preservation. J. Biomech. Eng. 1996, 1, 56-61. [CrossRef] [PubMed]

26. Ultimaker Cura. Available online: https:/ / ultimaker.com/software/ultimaker-cura (accessed on 10 May 2017).

27. Herbert, A.; Jones, G.L.; Ingham, E.; Fisher, J. A biomechanical characterization of acellular porcine super flexor tendons for use in anterior cruciate ligament replacement: Investigation into the effects of fat reduction and bioburden reduction bioprocesses. $J$. Biomech. 2015, 44, 22-29. [CrossRef] [PubMed] 